\title{
A EXPERIÊNCIA DO CONSÓRCIO CEDERJ E A DEMOCRATIZAÇÃO DO ENSINO SUPERIOR NO ESTADO DO RIO DE JANEIRO
}

Vittorio Lo Bianco ${ }^{(*)}$ Lia Faria $^{(* *)}$

O Consórcio Cederj começa a operar na década dos anos 2000, tendo como horizonte a concretização das ideias defendidas por Darcy Ribeiro em torno da criação de uma Universidade Aberta $^{1}$. Tratava-se, entretanto, de uma oferta regional, estruturada a partir da já existente Fundação CECIERJ, desde então administradora do Consórcio. Cabe à Fundação operacionalizar os recursos financeiros advindos do Tesouro Estadual e do financiamento federal, responsáveis pela concessão de bolsas. Compõem o Consórcio hoje: CEFET, IFF, UENF, UERJ, UFF, UFRJ, UFRRJ e UNIRIO. O total de alunos matriculados atualmente chega a quarenta e cinco mil, em quinze cursos de graduação a distância.

Em tese, a proposta do Consórcio gira em torno da otimização da gestão financeira e também dos polos ${ }^{2}$, das disciplinas de cada curso e dos modos de avaliação.

Concomitante a esses processos burocrático-pedagógicos, outros objetivos do Consórcio são destacados por Costa (2005): o estímulo à fixação da população no interior do estado; a formação de professores; o desenvolvimento econômico; a criação de parâmetros atentos à qualidade das graduações ofertadas a partir das metodologias da EaD.

\footnotetext{
${ }^{(*)}$ Servidor público estadual, Técnico em Ensino a Distância e Divulgação Científica na Fundação CECIERJ. Bacharel em Relações Internacionais pela PUC-Rio, Mestre em Políticas Públicas, Estratégias e Desenvolvimento pelo Instituto de Economia da UFRJ, especialista em Políticas Públicas (UFRJ) e em Gênero e Sexualidade (Instituto de Medicina Social/UERJ). Cursa, atualmente, Doutorado em Educação na Faculdade de Educação da UERJ. É pesquisador associado do Laboratório Educação e República (UERJ), atuando nas áreas de Cibercultura, Educação à Distância, ambientes virtuais de aprendizagem, Políticas Públicas, Globalização, Educação e Análise comparada.

${ }^{(* *)}$ Pós-doutora em Educação pela Universidade de Lisboa (2012) e em Ciência Política pelo IUPERJ (2008), doutora em Educação (UFRJ/1996), mestre em Filosofia da Educação IESAE/FGV (1989), bacharel e licenciada em História (UFRJ/1971) e graduada em jornalismo (UFRJ/1967). É professora associada de graduação e pós-graduação da UERJ/PROPED. Coordena o Laboratório Educação e República (LER) e é bolsista CNE/FAPERJ. Atua na área de educação, com ênfase em história da educação, gestão dos sistemas educacionais e memória fluminense.

${ }^{1}$ O conceito de Universidade Aberta está ligado aos usos das tecnologias da informação e da comunicação - online, a distância ou semipresencial. Darcy, na década de 1990, buscou em universidades européias o que havia de vanguarda na utilização de tecnologia da informação e da comunicação para a educação. Visitou a UNED, na Espanha, e a Open University, na Inglaterra.

${ }^{2}$ Até 2018.1 o Cederj contava com 32 pólos - centros regionais de apoio que contam com laboratórios, bibliotecas, salas de estudo e de aula para a tutoria presencial - espalhados pelo Estado do Rio de Janeiro.
} 
Nos limites deste texto, daremos destaque ao pensamento indisciplinado ${ }^{3}$ de Darcy Ribeiro, considerando sua relevância para a idealização do Cederj. Neste sentido, abordaremos a concepção darcyniana de Educação, atrelada à ideia de um projeto de nação. Tal projeto assenta-se na noção, desenvolvida pelo autor, de aceleração evolutiva, contrapondo-se ao que ele chama de modernização reflexa ${ }^{4}$.

A efetivação do Cederj, todavia, dar-se-á entre conformidades e rupturas com o pensamento de Darcy e, diante disso, algumas ponderações teórico-práticas precisarão ser feitas. Porém, é preciso reconhecer a intrínseca relação entre o que veio a ser o Consórcio e a idealização darcyniana de uma universidade do ar:

Minha universidade do ar é perfeita como um hospital sem doentes e sem médicos. Toda televisa e textual. Inspira-se na Open University, de Londres, e nas congêneres de Madri e Caracas. Criá-la é a perspectiva aberta pela Lei de Diretrizes e Bases da educação nacional que fiz aprovar no Congresso e que foi batizada de Lei Darcy Ribeiro. Nela restringe-se a frequência obrigatória, possibilitando o ensino a distância para os níveis primário, médio e superior. Isso representa perigo e uma ampla perspectiva de melhoria do ensino. Perigo porque se o ensino a distância se converter em máquina de fazer dinheiro, como ocorre na maioria das escolas privadas, será um desastre. Promessa porque possibilitará o Brasil recuperar 30 anos de atraso que tem nesta matéria, criando programas responsáveis de ensino a distância nos três graus. (RIBEIRO, 1997, p. 486).

É importante destacar a compreensão de Darcy sobre os perigos da mercantilização excessiva da $\mathrm{EaD}$, reconhecendo os usos perversos que poderiam ser feitos das tecnologias da informação e da comunicação a partir de um mercado ávido por lucros - já muito atuante nas escolas privadas. Mas Darcy também entendia, atento aos movimentos observados em outros países, que a aposta nessa nova modalidade de ensino poderia ser um instrumento para "recuperar 30 anos de atraso”, desde que implementado responsavelmente. Cabe-nos indagar, diante do projeto consolidado, até que ponto o Cederj se alinha às observações de Darcy e de que modo ele contribui para o fortalecimento da ideia de uma universidade necessária.

${ }^{3}$ Cf. BOMENY, Helena. Darcy Ribeiro: Sociologia de um indisciplinado. Belo Horizonte, UFMG, 2001.

“"Ao explicitar os fatores exógenos no desenvolvimento interno de sociedades, [Darcy Ribeiro] propõe os conceitos de “atualização histórica”, ou “modernização reflexa”, e de “aceleração evolutiva”. O primeiro define a inserção subordinada de povos "atrasados” em formações socioculturais estruturadas a partir de sistemas tecnologicamente superiores, implicando a perda da autonomia, pelo processo adaptativo, ou a destruição, quando se opta pela resistência, de entidades étnicas mais frágeis. Já o segundo conceito, “aceleração evolutiva”, traduz o desenvolvimento autônomo das sociedades na mobilização de fatores endógenos - e/ou exógenos - às situações que são peculiares aos novos povos”. (MIGLIEVICH-RIBEIRO; DA SILVA JR., 2008, p. 5). 


\section{A UNIVERSIDADE, OS INTELECTUAIS E O PROJETO DE NAÇÃO}

Para Darcy, a construção de uma universidade capaz de impactar diretamente na ampliação do conhecimento científico, sendo este uma ferramenta que impulsiona o desenvolvimento nacional, passa pela participação ativa dos intelectuais. Homem de seu tempo, Darcy temia que o desenvolvimento social e econômico do Brasil seguisse atrelado a modelos pré-concebidos em outros países e, por isso, insistia na universidade como lócus de um pensamento nacional, cônscio das nossas especificidades. Tal pensamento deveria ser crítico, autônomo e independente, ou seja, produzido em meio às demandas de nós mesmos, sem subalternizar-se às ideias vindas de fora.

Desde o projeto fundamental da UNB - também idealizado por Darcy - o autor se preocupou diretamente com a produção do conhecimento técnico-científico com foco nas características não apenas nacionais, mas também locais e regionais - o que será fundamental para a concepção da oferta de determinados cursos pelo Cederj em algumas cidades do interior do Estado do Rio de Janeiro. Sua defesa era por uma universidade que contestasse o status quo da sociedade, diminuindo as desigualdades. Deveria ser ela um instrumento político de intervenção direta do poder público e da sociedade civil organizada para o avanço social.

A ligação de Darcy Ribeiro com o desenvolvimento da EaD no país remonta às discussões travadas por ele enquanto Senador da República. Foi ele quem incluiu o tema no Plano Nacional de Educação - e em sua ação política - após conhecer a EaD praticada em centros de referência no exterior. A ideia era criar uma Universidade Aberta, desde os anos 1990, que resultaria no não concretizado Instituto Nacional de Educação a Distância Darcy Ribeiro (LACÉ, 2014).

A EaD a ser praticada no Brasil, segundo a concepção darcyniana, deveria contribuir para um avanço educacional pautado numa aceleração evolutiva. Com isso, o país poderia, finalmente, entrar em uma vanguarda tecnológica mundial, produzindo seus próprios modelos de $\mathrm{EaD}$. A Universidade Aberta, por ele projetada, seria uma força de expansão do ensino superior, de democratização do acesso, de acerto de contas com a nossa história de desigualdades. Nela, a pesquisa seria valorizada, comungando teoria e prática, de forma crítica, intervindo diretamente na realidade dos estudantes.

Feitas essas considerações, podemos sistematizar a concepção educacional de Darcy em termos do compromisso que a universidade deveria ter com um projeto de país. Tal concepção encontra afinidades nos escritos de Boaventura de Souza Santos e, por isso, passaremos a dialogar também com este autor. Nossa intenção é falar sobre a concretização do Direito à Educação, tendo como pano de fundo a experiência do Cederj. 


\section{NEOLIBERALISMO E DIREITO À EDUCAÇÃO}

De acordo com Castro (2015), a conjuntura política do momento de implementação do Consórcio Cederj, estava marcada por um governo federal alinhado a uma lógica neoliberal e, no plano estadual, tinha-se um governo por ele classificado como neopopulista. Disso derivou uma proposta de Consórcio que o autor considera conservadora, capaz

[...] de não considerar os conhecimentos prévios dos alunos, de imprimir discussões desconectadas das realidades educacionais locais e de exigir dos alunos muita memorização dos conteúdos estudados. Agrava tais fatores a questão de que o estudo é feito basicamente através das apostilas entregues aos alunos, gratuitamente, no início de cada semestre. Estas apostilas têm sido reproduzidas por diversos semestres, muitas vezes, sem renovação dos conteúdos nelas contidos (CASTRO, 2015, p. 111).

Castro ainda destaca a pressão de organismos internacionais, como o Banco Mundial, que insiste na EaD como solução para a expansão de um ensino voltado exclusivamente ao mercado de trabalho. Pesa nesta concepção o valor atribuído à Teoria do Capital Humano ${ }^{5}$ e a maximização de lucro para o setor privado com o menor custo possível.

Na esteira dos discursos e feitos neoliberais, Boaventura de Souza Santos (2005) reflete sobre os efeitos da globalização neoliberal à garantia de direitos, dentre eles o direito à educação. $\mathrm{O}$ autor aborda, especificamente, o caso da universidade pública, enfatizando a crise financeira que tem consequências diretas sobre as pesquisas. Darcy (1975), também pensando as crises da universidade, fala da crise de autonomia político-administrativa, marcada pela exigência de critérios de produtividade e eficiência, afeita à gestão empresarial.

As crises possuem, para Darcy, correlação direta com o projeto de nação que se quer desenvolver e sua superação viria, para ele, com a compreensão do papel desempenhado pela universidade: se ela estaria ao lado daqueles que pregam a manutenção do status quo, buscando se enquadrar naquilo que vem sendo desenvolvido em outros países ou se, ao contrário, ela se constituiria em instrumento fundamental para a mudança social, em um esforço para derrotar o neocolonialismo que, em tempos atuais, se disfarça de imposições externas como, por exemplo, de instituições financeiras internacionais como o Banco Mundial (NOLASCO-SILVA; LO BIANCO, 2017, p. 53).

\footnotetext{
${ }^{5}$ A Teoria do Capital Humano é uma formulação do Banco Mundial, construção ideológica, ao mesmo tempo em que responsabiliza o indivíduo pela desigualdade no acesso à educação e por sua condição socioeconômica, modifica a concepção republicana de educação ao afetar o caráter público, gratuito, laico e universal da educação, que passa a não ser mais compreendida como um direito social inalienável, sendo regida pelas leis de mercado (FRIGOTTO, 2017).
} 
O Banco Mundial, em relatório de 2002, sugere que os estados não aumentem o investimento público nas universidades, reduzindo o custo por estudante e substituindo, gradativamente, o ensino público pelo ensino privado (SANTOS, 2005). O mercado privado universitário, para Santos (2005), tem apresentado desafios complexos para pensar a educação, sobretudo ao incorporar as tecnologias da informação e da comunicação como ferramentas para a diminuição de $\operatorname{custos}^{6}$. Em que medida a oferta de EaD pública serve de contraponto a isso? Algo negativo que precisamos sublinhar, desde já, diz respeito ao precário processo de inclusão dos docentes $^{7}$ na cultura das TICs e, ainda mais grave, na cibercultura. Muitas vezes, optando por uma concepção tecnicista, as práticas de EaD enxergam as TICs como meras ferramentas que, bem exploradas, podem reduzir custos e oportunizar processos de formação de mão de obra de baixo custo a partir do trabalho de profissionais qualificados, mas também contratados como mão de obra de baixo custo.

Tais processos, oriundos de uma visão pouco alargada de EaD, colocam a modalidade em tela diante de um paradoxo: ao mesmo tempo em que anuncia o futuro, simulando um presente inovador, antenado, vale-se de procedimentos antiquados, conservadores, muito similares aos modos tradicionais de educação. Se, por um lado, ela é anunciada como possibilidade de inclusão, resposta para as desigualdades de acesso, como acreditava Darcy, por outro lado é, muitas vezes, marcada por velhas práticas pedagógicas pouco atentas às especificidades do estudante e, não menos importante, gerida a partir de critérios estabelecidos pelo grande capital - o que não resolve as desigualdades e, em alguma medida, pode aprofundá-las se considerarmos as barreiras impostas pela diversidade dos letramentos tecnológicos. Promessas da EaD como, por exemplo, a atenção à autonomia do estudante, nem sempre podem ser cumpridas, visto que há prazos, procedimentos, cobranças acadêmicas que inviabilizam a plena customização do próprio tempo, exigindo do estudante certos enquadramentos comportamentais e tecnológicos.

No Cederj, mesmo que parte da experiência se dê online, a partir do digital em rede, a alardeada autonomia dos atores conectados esbarra, por exemplo, em um sistema de

\footnotetext{
${ }^{6}$ A diminuição de custos tem a ver com o aumento da quantidade de alunos por professor, com a produção de material didático de baixo custo, com a precarização do trabalho de docentes e de tutores.

${ }^{7}$ A docência no Consórcio Cederj funciona por vínculo de bolsas de algumas categorias: O professor conteudista, contratado para escrever o conteúdo do curso, em especial o material impresso; O professor coordenador de disciplina, que, como o nome diz, coordena a disciplina no Ambiente Virtual de Aprendizagem do Cederj (o que inclui a coordenação de professores tutores); e professores tutores a distância e presencial (nos pólos).
} 
acompanhamento ${ }^{8}$ que monitora, dentre várias ações, quantidades de cliques e tempo que os atores gastam online na plataforma. Tal acompanhamento, como é de se esperar, foca no comportamento do usuário (se ele esteve online ou off-line num determinado tempo) e não na sua experiência concreta com/no ambiente virtual, suas aprendizagens, desafios, enfim, suas itinerâncias. No caso dos professores tutores, com seus vínculos precários e temporários, seria pouco razoável acreditar em altos níveis de engajamento na plataforma, visto que as tarefas por eles realizadas estariam mais próximas de um $j o b^{9}$ do que de um emprego.

\section{EAD, TECNOLOGIAS EDUCACIONAIS E A PRECARIZAÇÃO DO TRABALHO DOCENTE}

Podemos indagar, então, a partir de Darcy Ribeiro: que projeto de nação, ancorado numa proposta robusta de educação, poderá ser bem sucedido contando com trabalhadores temporários que têm por missão formar estudantes em áreas diversas, por meio de artefatos que demandam letramentos difíceis, sendo que eles próprios - os trabalhadores temporários - não foram suficientemente formados para operarem tais artefatos, nem lidarem com seus inúmeros desdobramentos? No Consórcio Cederj não há uma formação específica para os professores coordenadores de disciplinas, tampouco para os professores tutores, que dê conta dos diversos aspectos da modalidade.

Em um contexto de baixo engajamento, derivado de condições adversas de trabalho, muitos profissionais responsáveis pela criação e operacionalização das aulas abdicam ou negligenciam importantes processos da produção laboral. A interface entre design e educação, por exemplo, que pode proporcionar experiências mais significativas para os estudantes no ambiente virtual, fica a cargo dos designers instrucionais ${ }^{10}$ que, nem sempre, contam com a cocriação dos professores conteudistas. A relação, que deveria ser de criação e troca, acaba se tornando uma relação burocrática, protocolar e, por vezes, conflituosa, pautada em disputas pelo poder.

\footnotetext{
8 “O Acompanhamento Acadêmico é um projeto coordenado pela Diretoria Acadêmica com ações em parceria com a Diretoria de Material Didático e a Diretoria de Tutoria; tem como objetivo a supervisão sistemática do processo pedagógico e a promoção de ações integradoras entre os setores da Fundação Cecierj com as universidades consorciadas, a fim de otimizar o atendimento ao estudante e contribuir para sua permanência nos cursos de graduação do Consórcio Cederj [...]” (BIELSCHOWSKY, 2018, p. 150).

${ }^{9}$ O “job”, do inglês "serviço”, "trabalho”, em oposição a um emprego. “A flexibilidade hoje traz de volta esse sentido arcano de job, na medida em que as pessoas fazem blocos, partes de trabalho, no curso de uma vida.” (SENNETT, 2000, p. 9).

${ }^{10} \mathrm{O}$ trabalho do Designer Instrucional é promover as traduções necessárias para a transposição de ideias de uma plataforma para outra, auxiliando o professor e o aluno que se propõem a um curso desta natureza.
} 
O que percebemos, ao olhar para as relações praticadas no AVA do Cederj e, num cenário mais amplo, ao ouvir os discursos do grande capital sobre as funções mercadológicas da EaD, é um enorme descompasso entre experiências pedagógicas e expectativas de gestão. Enquanto sistemas de acompanhamento preocupam-se com cliques e tempos de permanência no ambiente de aula, os atores envolvidos nos cotidianos de cada curso praticam, em suas vidas extra-AVA ${ }^{11}$, as hipertextualidades da cibercultura - nem sempre viáveis na plataforma que, em linhas gerais, limita itinerâncias em rede. Um AVA mais amigável, aberto à conexão com outras redes poderia abrigar estratégias mais sensíveis à formação de vínculos entre os atores de cada curso, oportunizando situações mais afeitas à autoria coletiva e à troca de ideias. Também os professores, em um cenário de maior autonomia e estímulo às itinerâncias hipertextuais, poderiam apropriar-se com mais autoria do desenho didático dos seus próprios cursos, rompendo com práticas naturalizadas e limitadoras que, historicamente, conduzem o docente a operar comandos previamente estabelecidos. Tais comandos tendem a mudar quando mudam as coordenações de disciplina, por exemplo, sem considerar o histórico de cada profissional no Consórcio, suas experiências prévias, seus conhecimentos sobre o que deu certo e o que deu errado no ambiente. Neste sentido, é bastante revelador o depoimento de um interlocutor ${ }^{12}$ da pesquisa:

(T) É muito claro que a tutoria presencial acaba não funcionando como foi pensada. A meu ver, deveria haver mais integração entre os tutores a distância e os presenciais, com o presencial tendo um papel mais ativo do que tirar dúvidas, fazendo atividades práticas e grupos de estudo. Isso é especialmente negativo quando há troca da coordenação da disciplina, pois os professores podem mudar a forma de interação conosco como bem desejarem, isso quando estão dispostos a de fato coordenar a disciplina e não deixam tudo para fazermos. Para uma ação efetiva dos tutores é necessária uma coordenação dedicada, o que é raro de acontecer.

É salutar reconhecer que, quando falamos em tecnologias - e na EaD tecnologia é um conceito fundamental - não estamos nos referindo unicamente aos equipamentos e aos softwares,

\footnotetext{
${ }^{11}$ Ambiente Virtual de Aprendizagem. Espaço virtual onde se dá o processo de ensino-aprendizagem, as interações professor x estudante e estudante x estudante. No caso do Cederj, utiliza-se uma customização do sistema Moodle (AVA gratuito disponível para customização).

${ }^{12}$ Neste trabalho, as falas dos interlocutores da pesquisa foram agrupadas seguindo metodologia desenvolvida por NOLASCO-SILVA (2018) em sua tese de doutorado. Ele chama de praticantes-alegóricos a reunião de diversos interlocutores sob um mesmo pseudônimo, de modo a produzir na pesquisa uma função-informante que ilustre condutas e processos de subjetivação. Como a nossa proposta de pesquisa não gira em torno da biografia dos interlocutores, mas dos entrecruzamentos de suas experiências na EaD, a edição de suas falas em blocos temáticos auxilia o desenrolar de um fio argumentativo, ao mesmo tempo em que ilustra os processos que desejamos evidenciar. Utilizaremos as falas dos interlocutores em itálico, com o código (P) antes das falas dos professores coordenadores de disciplina, (T) para os professores tutores e (E) para os estudantes do Consórcio Cederj.
} 
mas também às práticas, aos usos realizados por cada praticante cultural. O debate sobre tecnologias deve abranger também um pensamento crítico sobre as relações estabelecidas entre a máquina e o humano, o que vincula a tecnologia à didática e à cultura (PAIVA, 2010). Em outras palavras, mais que usuários de tecnologias, os profissionais que atuam no Cederj deveriam ser vistos como produtores de tecnologias, visto que, em suas práticas cotidianas de docência eles criam estratégias de mediação entre os conhecimentos e os estudantes, produzem trilhas que não são, necessariamente, as trilhas previstas ou indicadas pelo sistema. Contudo, tais ações criadoras, características de uma docência artesanal (NOLASCO-SILVA, 2018) ${ }^{13}$, ficam ameaçadas em contextos de precarização do trabalho.

O vínculo do decente com o Consórcio - por bolsa, sem direitos trabalhistas previstos - é extremamente frágil e não colabora para o desenvolvimento de um sentimento de pertencimento. Aqui, como dissemos acima, vale a lógica do job (SENNETT, 2000) e não a do emprego - sem direitos trabalhistas, como a aposentadoria (CASTRO, 2016).Para agravar a situação, ainda temos a falta de investimento público, derivada da alegada crise do estado do Rio de Janeiro que, entre muitas e nocivas consequências, submete os profissionais do Cederj aos constantes atrasos dos pagamentos. Sobre a “crise” no Estado do Rio de Janeiro, Nolasco-Silva e LoBianco (2017, p. 49) argumentam que:

Na matriz dos problemas [...] está a fabricação da ideia de “crise” que, na voz da grande mídia e dos grupos políticos que coordenam o Estado, tudo justifica e tudo autoriza, inclusive sufocar, imobilizar, deteriorar, sucatear, impedir o funcionamento, impondo racionamentos e construindo argumentos que atestam a irrelevância das universidades públicas e demais instituições afins. São elas, no caso do Rio de Janeiro, que recebem o primeiro corte, o primeiro atraso de pagamento, a falta de informação. A Secretaria de Ciência, Tecnologia e Inovação - que no exercício da crise passou a se chamar Secretaria de Ciência, Tecnologia e Desenvolvimento Social, depois de uma fusão com a Secretaria de Assistência Social e Direitos Humanos - é sempre a primeira a receber o sinal do desfinanciamento público. Subordinada a essa secretaria estão, no âmbito da Ciência e da Tecnologia, a Universidade do Estado do Rio de

\footnotetext{
13“'A ideia de docência artesanal [...] devolve aos professores a sua potência enquanto trabalhadores - criativos que vendem sua força de trabalho sem, no entanto, abrir mão das autorias daquele processo. Os professores, na perspectiva do artífice, são trabalhadores críticos do sistema capitalista, defensores de uma escola insubordinada às tentativas de modelizações capitalísticas (GUATTARI; ROLNIK, 2005), pois promotora de processos de singularização. Os manuseios tecnológicos, nesse sentido, cumprem tarefas de desorganização e não de assentamento. As tecnologias educacionais precisam fazer falar, pensar, questionar ordens estabelecidas, fomentando novas realidades criadas a partir das palavras e dos gestos nascidos e, ao mesmo tempo, produtores do desejo - um desejo costurado coletivamente” (NOLASCO-SILVA, 2018, p. 194).
} 
Janeiro (UERJ), a Universidade Estadual do Norte Fluminense Darcy Ribeiro (UENF), a Universidade Estadual da Zona Oeste (UEZO), a Fundação Centro de Educação a Distância e Divulgação Científica (CECIERJ), a Fundação de Apoio a Escola Técnica (FAETEC) e a Fundação de Amparo a Pesquisa do Estado do Rio de Janeiro (FAPERJ). Em tempos de “crise”, cuja razão principal, de acordo com a narrativa oficial, é a queda na arrecadação dos royalties do petróleo, devemos indagar por que uma secretaria, que poderia nos auxiliar a escapar dessa situação de dependência, é exatamente uma das mais prejudicadas? Por que as ações “emergenciais”, devido ao decreto de calamidade pública, atingem principalmente as instituições de nível superior?

Os problemas e desafios elencados até aqui, ainda que tenham sido estudados tendo o Consórcio Cederj como pano de fundo, são recorrentes em outras instituições que praticam a EaD como modalidade educacional. São questões referentes ao trabalho na EaD, concernentes a uma cultura que associa a educação a distância à vínculos laborais precários, subordinados à maximização dos lucros ou, no caso da EaD pública, submetidos à redução de custos - uma vez que educação, para os governos de princípios neoliberais, não é investimento, mas gasto.

\section{O CEDERJ, O DIREITO À EDUCAÇÃO E A DEMOCRATIZAÇÃO DA UNIVERSIDADE PÚBLICA}

A percepção do ensino superior como antessala do mercado de trabalho, afeta diretamente a rotina laboral do professor. Nessas circunstâncias, ele deixa de ser um idealizador de itinerâncias didáticas e passa a ser um executor de procedimentos, preocupado com o alcance de metas, subordinado a processos de avaliação externa que pode ditar o rumo dos financiamentos da instituição em que atua e, em alguns casos, pode interferir em seus próprios salários - vide algumas secretarias de educação que bonificam os professores de turmas bem avaliadas. Este professor cumpridor de metas tem menores oportunidades de praticar uma docência artesanal, um trabalho mais afeito à práxis ${ }^{14}$, resistente à alienação ${ }^{15}$.

Um professor artífice que atua na EaD entende que a Cibercultura altera profundamente os nossos processos de formação; compreende que as tecnologias não são neutras e que há interesses políticos e econômicos em sua adoção nas escolas e universidades. Mas há também usos possíveis e criativos a partir delas, há práticas de autorias e outros modos de comunicação. O artífice da EaD

\footnotetext{
${ }^{14}$ É o trabalho com sentido, imerso no mundo da vida, constituidor das utopias do trabalhador. A práxis é a ação dos instrumentos que podem modificar as estruturas sociais. (MARX, 2005).

${ }^{15}$ A não identificação do trabalhador com o processo e com o produto do seu trabalho (MARX, 2004).
} 
faz o desenho didático do AVA de sua disciplina, customiza suas aulas na interação com os estudantes, amplia as telas, alarga os sentidos do ato de estudar. Ensina a aprender com a máquina. Aprende a ensinar com a máquina. Sabe que a máquina só existe porque nós existimos. Mas, como ser um professor artífice da EaD na ausência, às vezes, das condições básicas de existência?

(T) A forma de contratação dos profissionais que trabalham no Consórcio é hoje um dos grandes gargalos da instituição, sem sombra de dúvidas. É necessário concurso público para os profissionais efetivos, tanto para tutores quanto para coordenadores de disciplina e de curso. Além de impactar na qualidade do serviço oferecido aos estudantes, a alta rotatividade atrapalha o andamento das disciplinas. Na forma de contrato atual estamos há anos sem nenhum reajuste, além dos constantes atrasos. Não temos pagamento de auxílio transporte e alimentação, $13^{\circ}$, férias, licença e nenhum outro direito trabalhista. Sentimos que nosso trabalho não é valorizado, pois não há investimento em nossa qualificação. Muitos polos contam com uma infraestrutura precária, o que impacta em nosso trabalho.

O depoimento acima - muito recorrente nas falas dos professores tutores e, também, uma bandeira antiga da Associação dos Docentes em Educação a Distância do Rio de Janeiro (Adopead) - sublinha a precariedade do vínculo que os docentes possuem com a Fundação Cecierj. Mesmo assumindo um discurso que liga formação à melhores colocações no mercado de trabalho, o Consórcio tem a sua prática marcada por baixas remunerações e inobservâncias de direitos trabalhistas.

A relação entre os egressos do Cederj e o mercado de trabalho pode ser apreendida a partir das interações abaixo, netnografadas ${ }^{16}$ em espaços digitais de interlocução.

\footnotetext{
${ }^{16} \mathrm{~A}$ netnografia consiste em uma etnografia virtual pautada na observação e na interação digital entre sujeitos que habitam o ciberespaço. O Consórcio CEDERJ conta com variados espaços de convivência online entre alunos, tutores e outros profissionais envolvidos na EAD.
} 
Figura 1. Debate no grupo “Cederj” no Facebook sobre a inserção dos estudantes do Cederj no mercado de trabalho.

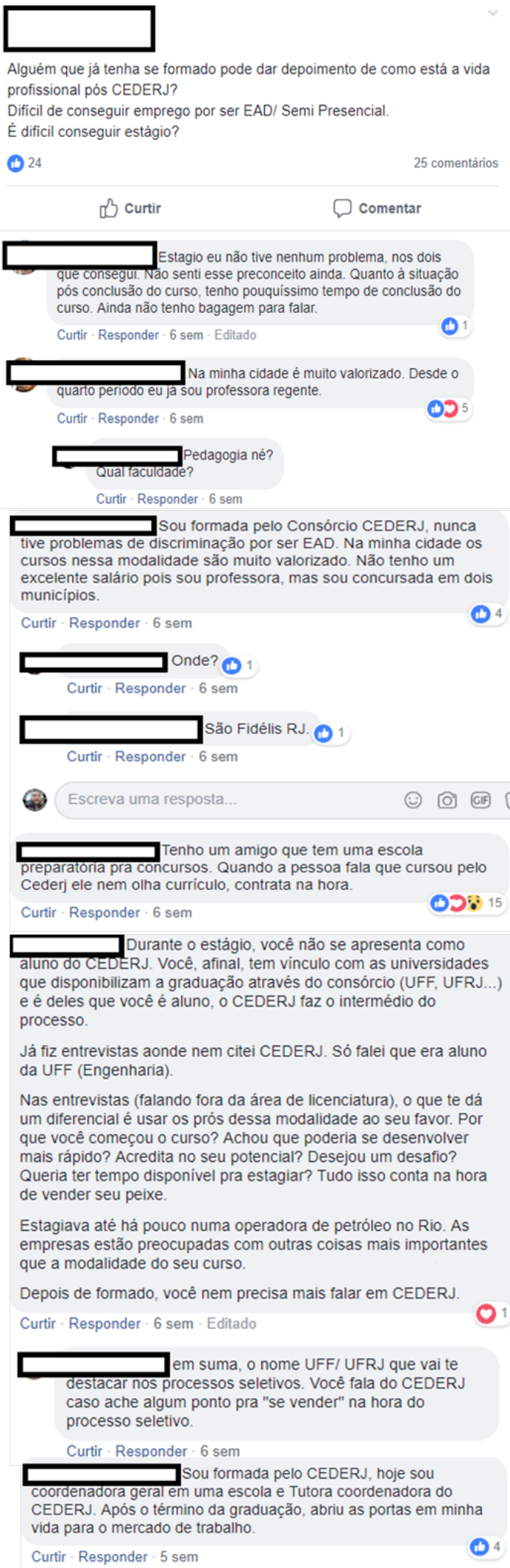

Fonte: <https://www.facebook.com/groups/cederj.membros/?ref=br_rs/>. Acesso em: 05/08/2018. 
Nas interações supracitadas, extraídas do grupo “Cederj” no Facebook, os estudantes do Consórcio debatem sobre a empregabilidade dos licenciados. Há um destaque para a absorção de licenciados nas cidades do interior do estado do Rio de Janeiro. Há também apontamentos sobre a relevância do nome das universidades públicas consorciadas. Esses nomes, dizem alguns, funcionariam como elemento de vantagem para a inserção profissional, uma marca de distinção. A conversa continua:

Figura 2. Debate no grupo “Cederj” no Facebook sobre a inserção dos estudantes do Cederj no mercado de trabalho.

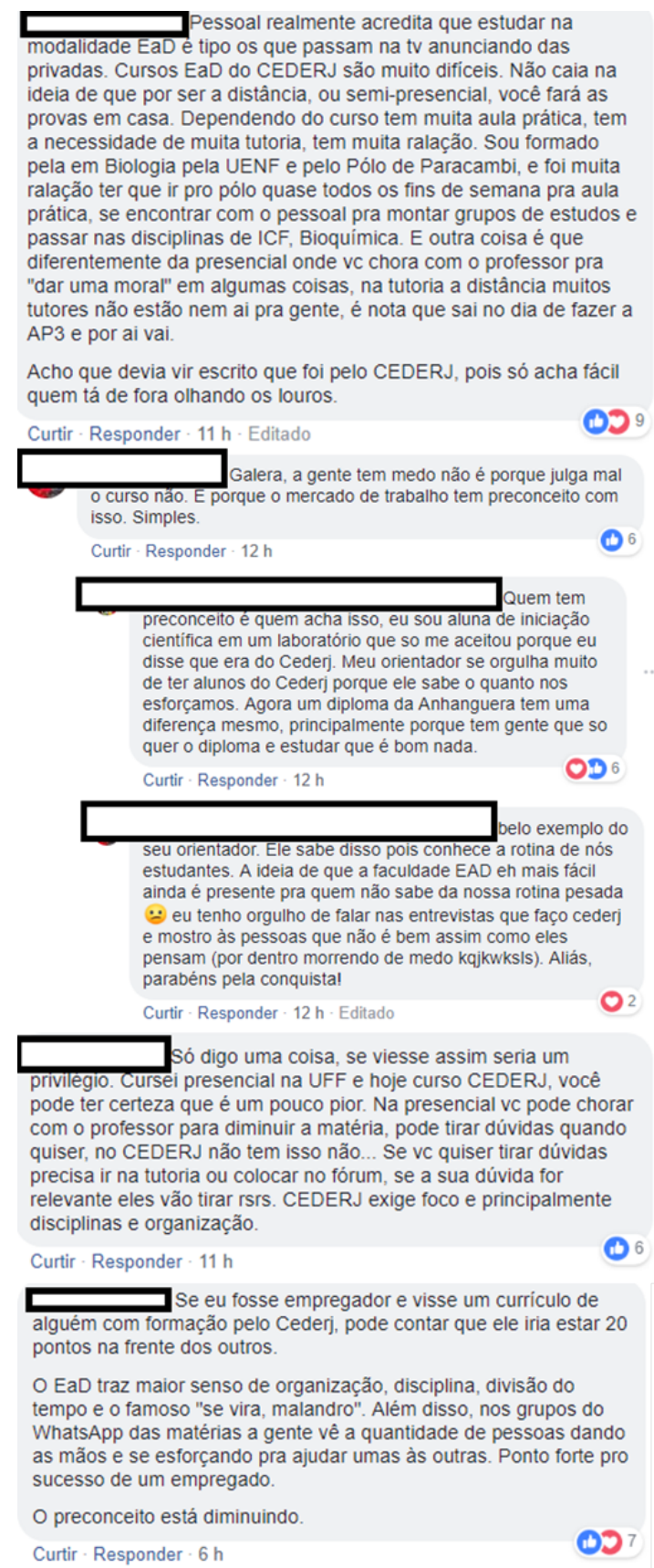

Fonte: <https://www.facebook.com/groups/cederj.membros/?ref=br_rs/>. Acesso em: 05/08/2018. 
No debate acima a reflexão dos estudantes diz respeito ao senso comum de que a modalidade EaD seria "mais fácil”, em especial com o registro da oferta da modalidade no setor privado. Há também considerações sobre as vantagens e as desvantagens da modalidade a distância em comparação com o ensino presencial. Ressalta-se ainda que a falta de apoio institucional conforme relatado pelos interlocutores no que se refere a um apoio mais constante tanto em termos acadêmicos quanto em termos técnicos - faz com que o estudante tenha que desenvolver um "senso de organização” e de colaboração.

(E) Não nos sentimos parte das Universidades às quais estamos vinculados, o que se revela desde a ausência de um documento como uma carteirinha, em muitos casos, até a falta de acesso a oportunidades de bolsa de pesquisa e iniciação científica, por exemplo.

É possível constatarmos que há um alto índice de empregabilidade em determinadas áreas. Há, por exemplo, a observação - de acordo com os relatos dos interlocutores - de que estudantes formados em licenciaturas do Cederj pelo interior do Estado se dão bem nos concursos que realizam, seja pela quantidade de concursos para licenciados, seja pela qualidade da formação que receberam.

Por tudo o que discutimos até aqui, é possível pensar que a EaD praticada no Consórcio Cederj esteja alinhada aos anseios de Darcy Ribeiro de ampliar o atendimento educacional das camadas mais pobres da população do estado. Mas há que se levar em conta que este público (atendido pelo Cederj) sofreu alterações importantes nos últimos tempos, sobretudo no campo do acesso à internet/computador/telefonia móvel.

Hoje, por exemplo, 93,8\% dos estudantes do Cederj alegam possuir aparelho celular com conexão de internet e mais de 60\% utilizam banda larga com mais de 2 MB para a utilização da plataforma Cederj/Moodle ${ }^{17}$, o que nos apresenta um quadro de acesso (apesar disso não significar, necessariamente, inclusão digital, no sentido de saber utilizar os recursos disponíveis online de forma profícua para os estudos). Esse estudante, cada vez mais conectado, se torna mais demandante de uma política pública que atenda aos seus anseios por uma formação de qualidade, condizente com os hábitos tecnológicos da atualidade.

(E) Há uma necessidade urgente de mais interatividade na plataforma do Cederj, utilizando mais recursos educacionais (muitas vezes há apenas PDF para seguirmos o curso). Vemos uma desmotivação generalizada entre os funcionários e professores,

\footnotetext{
${ }^{17}$ Fonte: Avaliação Institucional do Consórcio Cederj de 2017.2.
} 
principalmente aqueles que atendem presencialmente. Não sei se isso se deve ao tipo de contrato que eles possuem com a instituição.

No depoimento acima, destaca-se a percepção de um problema de interatividade, de subutilização do potencial pedagógico (e tecnológico) da EaD praticada no Consórcio Cederj. Critica-se o que podemos chamar de uma colonização da EaD pelas práticas conservadoras do ensino presencial, de caráter instrucionista, que lidam com as tecnologias na perspectiva do consumo.Processos de inclusão digital dão lugar a treinamentos que, quando muito, permitem uma alfabetização digital (familiarização com comandos básicos a respeito do funcionamento objetivo da plataforma online) e não processos de letramentos digitais (que têm a ver com certa fluência na cultura digital e na cibercultura, principalmente).

A EAD praticada no Cederj, ainda imersa em princípios muito dependentes das práticas presenciais e conservadoras de educação, não leva em consideração movimentos comuns da cultura contemporânea, derivados de uma fruição tecnológica intensa. Enquanto praticamos a mobilidade, a internet nas coisas, a ubiquidade, as trocas nas redes sociais, a liberação do pólo de emissão, ainda temos AVAs projetados como depósitos de PDF, afeitos a linearidade dos trajetos de estudo, alheios à hipertextualidade.

O que os interlocutores da pesquisa apontam é que há uma desatualização sobre o perfil econômico-cultural do estudante do Cederj, tendo a instituição parado, ao longo dos anos, em uma noção de um estudante de baixa renda, digitalmente excluído, ignorando que há, cada vez mais, pessoas buscando uma segunda graduação ou já incluídas no mercado de trabalho. A diversidade do corpo discente do Cederj fica clara quando sabemos que:

(E) Busquei o Cederj pensando que a EaD poderia ser útil para pessoas como eu e outros colegas que trabalhamos, porém, a realidade não é exatamente essa. As Avaliações demandam muita atenção, pois claramente não há uma coordenação entre professores coordenadores e tutores, não há um planejamento adequado em muitas disciplinas que dê conta da quantidade de horas que cada um terá que se dedicar por disciplina. O material didático impresso está constantemente defasado, apesar de ser ainda importante, e não dialoga com a necessidade de tempo.

No depoimento acima, o interlocutor fala da relação estudo/trabalho, se referindo à promessa da EaD de flexibilizar o tempo, mas essa flexibilização nem sempre migra da teoria para a prática. 


\section{CONSIDERAÇÕES FINAIS}

Se pensarmos, exclusivamente, no desejo de Darcy em expandir a oferta do ensino superior no Estado do Rio de Janeiro, podemos dizer que o Cederj cumpre essa função. O consórcio ainda logra em manter os estudantes nas suas cidades de origem, condição também defendida por Darcy em seu projeto educacional. A fixação dos quadros universitários no interior auxilia tanto na questão da renda individual - evitando os gastos de instalação e manutenção de uma vida em outra cidade - quanto no desenvolvimento regional - ampliando a oferta de mão de obra qualificada.

No entanto, ainda estamos longe de superar as distâncias entre as universidades e os estudantes. Na interlocução com os participantes da pesquisa podemos perceber na experiência do Cederjuma concepção de educação muito pautada no modelo tradicional, presencial. A superação da 'distância' tem a ver com uma nova perspectiva sobre a questão da tecnologia e da cibercultura e os entrelaçamentos disso com a educação formal. Não se ensina com as tecnologias usando-as como fim em si mesmo. As tecnologias são disparadoras de relações sociais. Na EAD elas são meio, mas também são mensagens. E deveriam ser customizáveis, percebidas a partir dos usos de cada praticante (CERTEAU, 1994) e não por meio de suas funções “duras”, descritas em manuais de instruções.

Outro ponto relevante a ser superado é aquele ligado à falta de vínculos entre as pessoas ou a falta de estímulo à criação de vínculos. É difícil construir na EAD um sentimento de comunidade, de pertencimento. Não só entre os estudantes e a universidade, enquanto instituição, mas também entre as pessoas de uma mesma turma, por exemplo. Recursos educativos como os fóruns não são percebidos como um lugar de encontro, por mais que facilitem a interação, por serem espaços protocolares e reativos - o estudante participa por ser cobrado a participar com vistas a sua avaliação. No diálogo com um professor percebemos essa questão:

(P) Entendo ser ainda um desafio do Consórcio a distância existente entre os professores e os estudantes. Isso também vale para a relação entre os polos e as Universidades, o que gera um “não pertencimento” ao estudante. É necessário um maior reconhecimento ao estudante do Cederj por parte das Universidades.

A partir de Boaventura (2006), um caminho teórico que nos parece pertinente é aquele que fala da ecologia dos saberes ${ }^{18}$, construindo uma alternativa ao neoliberalismo, com a participação

\footnotetext{
${ }^{18} \mathrm{~A}$ ecologia dos saberes consiste em um conjunto de epistemologias marcadas pela possibilidade da diversidade de pensamento fora do eixo central, como resistência à globalização neoliberal, exercendo diretamente o papel de globalização contra-hegemônica. Há a valorização não apenas do conhecimento científico-acadêmico, mas da interação
} 
ativa dos atores que compõem a luta pelo ensino superior público de qualidade - professores, servidores, sindicatos, partidos e movimentos sociais. Para isso, a Universidade - incluindo o Consórcio com as especificidades da modalidade a distância - precisaria se abrir aos grupos historicamente excluídos, acolhendo-os não apenas como sujeitos em formação, carentes de uma ilustração a ser conquistada através da universidade, mas também como sujeitos do conhecimento, constituídos por saberes diversos que interessam, que não são dispensáveis, pois constituintes das redes de significações.

É preciso reconhecer que a crença nos intelectuais como agentes exclusivos da mudança social não encontra respaldo na história recente. Nem os próprios intelectuais acreditam nisso. A universidade, se quiser assumir um papel protagonista na formação de um novo país, precisará ser lócus de uma aposta na ecologia dos saberes, rompendo com as hierarquias clássicas acerca do conhecimento, valorizando as histórias e as bagagens dos distintos públicos que a compõem, incluindo a sociedade em que está inserida. A universidade precisa se abrir para o mundo, para a diversidade e para as especificidades das relações que construímos com as tecnologias, sobretudo uma universidade do ar, como nomeou Darcy Ribeiro.

Entre as muitas leituras possíveis acerca das “crises” da universidade, apostar na ecologia dos saberes, no somatório de forças dos sujeitos que constituem a Academia, parece-nos um caminho mais democrático do que aquele que sugere a salvação pela via da mercantilização do ensino, da privatização ou das parcerias público-privadas.

A EaD, no modelo do Cederj, no entanto, ainda enfrenta desafios no que tange a necessária politização da construção de uma “Universidade Necessária”, já que no modelo do Consórcio não há uma organicidade entre as universidades e, tampouco, entre os estudantes, os professores e demais sujeitos. A Universidade Necessária seria constituída pela ação dos intelectuais orgânicos ${ }^{19}$. Estes se dedicariam a construção de uma universidade não apática politicamente, engajada na luta por um modelo autônomo de desenvolvimento.

No entanto, os docentes do Consórcio - e são variados os tipos de docentes - estão submetidos a procedimentos que engessam as suas práticas, que limitam as suas autorias. Como desenvolver um pensamento autônomo, contraposto ao hegemonicamente estabelecido, se os meios de produção possuem tantos direcionamentos e tão poucas brechas para customizações? Como

deste com o conhecimento produzido localmente, o que contribuiria para fortalecer e dar credibilidade à produção do conhecimento em geral.

${ }^{19}$ Intelectual orgânico é um conceito de Gramsci (2001) que procura compreender a ação intelectual conectada à ação política a fim de desenvolver uma consciência crítica nos trabalhadores, organizando a luta e a ação política. 
subverter as normas, produzindo rebeldias epistêmicas e didáticas, em um cenário de precarização do trabalho? O intelectual orgânico resiste aos constantes atrasos de salário? Resiste aos não reajustes? Resiste ao achincalhe da profissão?

A vinculação da Fundação Cecierj / Consórcio Cederj com a política local pela disputa de verbas, interesses e nomeações de cunho político ainda a mantém no ciclo de (des)continuidades ${ }^{20}$ da política educacional fluminense. No caso da Fundação Cecierj, essas mudanças atingem especialmente as questões de financiamento estadual e a gestão dos pólos, parte deles ligados às prefeituras locais, pois, no caso da gestão central da instituição, há uma continuidade - rara no Estado do Rio de Janeiro - há mais de uma década. Cabe ressaltar que,historicamente, o estado do Rio de Janeiro tem as suas políticas públicas - com destaque para as educacionais - marcadas pela descontinuidade das gestões, fruto da disputa política.

Mesmo com todos os problemas apresentados, apesar dos desafios em aberto, ainda é possível afirmar que a experiência do Consórcio Cederj representa um contraponto potente à mercantilização da EAD no país, preconizada por organismos internacionais como o Banco Mundial, apesar de reproduzir práticas do setor privado, como a desvalorização da função docente. $\mathrm{AEaD}$, com todos os problemas e desafios elencados neste texto, tem sido considerada na reestruturação de outros níveis de ensino. Ainda não é uma realidade, mas demanda atenção porque foi promessa de campanha do governo que ganhou as eleições em nível federal.

No modelo pensado por Darcy, a universidade é financiada pelo Estado porque serviria para pensar em soluções que mantivessem o estado de pé, em pleno funcionamento. A universidade existe para pensar o Brasil, afirmava Darcy. Em caso de financiamento privado, como defendeu o Ministro do Supremo Tribunal Federal, professor da UERJ, Luís Roberto Barroso ${ }^{21}$, a quem serviria a universidade?

Seguimos na luta pela efetivação dos direitos humanos, com protagonismo de responsabilidade cabível ao poder público, com destaque para os direitos econômicos, sociais e culturais - apesar da noção da indivisibilidade de direitos - conjugando a ideia de direitos com alcance global e o respeito às particularidades locais, o que está diretamente ligado ao direito à educação, incluindo o ensino superior enquanto ferramenta de inclusão e redução de desigualdades.

\footnotetext{
${ }^{20}$ Cf. FARIA, Lia. Chaguismo e Brizolismo: Territorialidades políticas da escola fluminense. Rio de Janeiro: Quartet; Faperj, 2011.

${ }^{21}$ Disponível em: <https://oglobo.globo.com/opiniao/crise-na-uerj-reacende-debate-sobre-universidade-gratuita-208065 $68>$.
} 
Nos limites deste trabalho, problematizamos algumas premissas que merecem ser observadas quando falamos em políticas educacionais que apostam na $\mathrm{EaD}$ como instrumento de ampliação do acesso ao Ensino Superior. Em tempos em que a EaD ganha destaque, sendo apontada como solução para parte dos problemas educacionais, é preciso ponderar para que ela não seja parte do problema. A democratização do acesso ao ensino superior é um desafio para todas as modalidades de ensino e a EaD, devido as suas especificidades, pode contribuir para a operacionalização desde processo. Mas antes será necessário reconhecer que o "a distância" do nome não significa distanciamento, mas mobilidade que, se bem praticada, estimula a autonomia. Autonomia, contudo, não significa isolamento e solidão, ao contrário. É liberdade para fazer junto, em rede, em qualquer lugar, a qualquer momento. É mais autoria, cocriação e menos comandos. É entender o virtual como virtualidade, como o que pode vir a ser. É itinerância hipertextual. É docência artesanal e discência conectada - com a máquina, com o mundo, com o outro. 


\section{REFERÊNCIAS}

BIELSCHOWSKY, Carlos et al. Fundação Cecierj: ontem, hoje e amanhã. Rio de Janeiro :CECIERJ, 2018.

BOMENY, Helena. Darcy Ribeiro: Sociologia de um indisciplinado. Belo Horizonte: UFMG, 2001.

CASTRO, Leonardo Villela de: Encontro dos Rios: Um estudo comparado da formação de professores de educação infantil em dois cursos de pedagogia, presencial e a distância, da UNIRIO. Tese (Doutorado em Educação) Universidade Federal do Rio de Janeiro, Faculdade de Educação, Programa de Pós-Graduação em Educação, 2015.

Professores “invisíveis”? Lutando por uma educação sem distância alguma. Revista Contemporânea de Educação, vol. 11, n. 21, jan./jul. de 2016.

COSTA, Celso. Licenciaturas a distância - a experiência do Cederj. Rio de Janeiro: UFF, 2005.

FARIA, Lia. Chaguismo e Brizolismo: Territorialidades políticas da escola fluminense. Rio de Janeiro: Quartet; Faperj, 2011.

FRIGOTTO, Gaudêncio. A gênese das teses do Escola sem Partido: esfinge e ovo de serpente que ameaçam a sociedade e a educação. In: FRIGOTTO, Gaudêncio. (Org.). Escola “sem” Partido. Esfinge que ameaça a educação e a sociedade brasileira. Rio de Janeiro: UERJ; LPP, 2017. p. 17-34.

GRAMSCI, A. Cadernos do cárcere. Rio de Janeiro: Civilização Brasileira, 2001. v. 1.

LACÉ, Andréia Mello. A Universidade Aberta do Brasil (UAB): das origens na ditadura militar ao século XXI. Tese (Doutorado em Educação) - Faculdade de Educação, Universidade de Brasília, Brasília, 2014.

MARX, Karl. Manuscritos econômico-filosóficos. São Paulo: Boitempo Editorial, 2004.

Teses sobre Feuerbach (1945). E-book. Edição RidendoCastigat Mores, 2005. Disponível em: <http://www.ebooksbrasil.org/adobeebook/feuerbach.pdf $>$.

MIGLIEVICH-RIBEIRO, Adelia; da SILVA JÚNIOR. Paulo Sérgio Ribeiro. A UENF e seu plano orientador entre a “modernização reflexa” e a "aceleração evolutiva”: notas sobre o pensamento de Darcy Ribeiro. AgendaSocial. Revista do PPGPS/UENF, Campos dos Goytacazes, v. 2, n. 2, p. 1-2, mai./set. 2008.

NOLASCO-SILVA, Leonardo. Os olhos tristes da fita rodando no gravador: as tecnologias educacionais como artesanias docentesdiscentes. 122 f. Tese (Doutorado em Educação) - Faculdade de Educação, Universidade do Estado do Rio de Janeiro, Rio de Janeiro, 2018.

PAIVA, Laureana G. de. Do giz colorido ao data show: uma conex@aodescontect@d@. Juiz de Fora: UFJF, 2010.

RIBEIRO, Darcy. A universidade necessária. São Paulo: Paz e Terra, 1991.

Confissões. São Paulo: Cia das Letras, 1997.

. A Universidade e a Nação. Separata de Educação e Ciências Sociais, v. 10, n. 19, jan./abr. 1962.

. La universidad latino-americana y el desarrollo social. In: URUGUAY. Uruguay una política de desarrollo: VIII cursos de verano. Montevideo: Universidad de la República, 1966. p. 269-316.

(Org.). Universidade de Brasília: projeto de organização, pronunciamento de educadores e cientista e Lei $n^{\circ}$ 3.998 de 15 de dezembro de 1961. Brasília, DF: Ed. da UnB, 2011.

SANTOS, Boaventura de Sousa. A gramática do tempo: para uma nova cultura política. São Paulo: Cortez, 2006.

A Universidade no Séc. XXI: Para uma Reforma Democrática e Emancipatória da Universidade. 3. ed. São Paulo: Cortez Editora, 2004.

. Tensões da Modernidade. Faculdade de Economia da Universidade de Coimbra e Centro de Estudos Sociais. 1995.

SANTOS, Edmea. Saberes da docência online: dialogando com a epistemologia da prática e com os saberes dos professores-tutores da UERJ-Cederj. In: MILL, Daniel; MACIEL, Cristiano. (Org.). Educação a Distância: elementos para pensar o ensino-aprendizagem contemporâneo. Cuiabá: EDUFMT, 2013. v. 1, p. 125-144.

SENNETT, R. O artífice. 3. ed. Rio de Janeiro: Record, 2009. 
SENNETT, R. A corrosão do caráter: consequências pessoais do trabalho no novo capitalismo. Rio de Janeiro: Record, 2000.

\section{RESUMO}

A proposta deste trabalho é refletir, a partir dos estudos de Darcy Ribeiro em "A Universidade Necessária” (1991) em diálogo com outros autores contemporâneos, sobre o lugar da modalidade 'Educação a Distância' na ampliação da oferta educacional de nível superior no Estado do Rio de Janeiro. Para isso, analisamos a trajetória do Centro de Educação a Distância do Estado do Rio de Janeiro (Cederj) e sua conexão com o pensamento-ação de Darcy Ribeiro - entusiasta da EaD num tempo em que a modalidade ainda não era considerada no âmbito das políticas públicas de educação. Ao traçar as linhas gerais dos caminhos e descaminhos do Cederj, indagamos sobre os desafios que se apresentam e sublinhamos sua potência enquanto via de acesso ao ensino superior por milhares de estudantes.

Palavras-chave: Universidade. Darcy Ribeiro. EaD. Cederj.

\section{THE CEDERJ CONSORTIUM EXPERIENCE AND THE DEMOCRATIZATION OF HIGHER EDUCATION IN THE STATE OF RIO DE JANEIRO}

\section{ABSTRACT}

The proposal of this work is to reflect, based on the studies of Darcy Ribeiro in "A Universidade Necessária" (1991) in interaction with other authors about the place o distance learning in the expansion of the educational offer of higher education in the State of Rio de J aneiro. For that, we analyse the trajectory of the Center for Distance Education of the State of Rio de Janeiro (Cederj) and its connection with Darcy Ribeiro's thought-action - who was an enthusiast of distance learning in a time when the modality wasn't considered yet amongst the public policies of education. In tracing the general lines of Cederj's way sand mis places, we inquire about the challenge sthat we face and underline its power as a way of access to higher education by thousands of students.

Keywords: University. Darcy Ribeiro. Distance Learning. Cederj.

\section{LA EXPERIENCIA DEL CONSORCIO CEDERJY LA DEMOCRATIZACIÓN DE LA ENSEÑANZA SUPERIOR EN EL ESTADO DEL RÍO DE JANEIRO}

\section{RESUMEN}

La propuesta de este trabajo es reflexionar, a partir de los estudios de Darcy Ribeiro en "A Universidade Necessária" (1991) en diálogo con otros autores contemporáneos, sobre el lugar de la modalidad 'Educación a Distancia' en la ampliación de la oferta educativa de nivel superior en el Estado de Rio de Janeiro. Para ello, analizamos la trayectoria del Centro de Educación a Distancia del Estado de Río de Janeiro (Cederj) y su conexión con el pensamiento-acción de Darcy Ribeiro - entusiasta de $\mathrm{EaD}$ en un tiempo en que la modalidad aún no era considerada en el ámbito de las políticas públicas de educación. Al trazar las líneas generales de los caminos y descaminos del Cederj, indagamos sobre los desafíos que se presentan y subrayamos su potencia como vía de acceso a la enseñanza superior por miles de estudiantes.

Palabras clave: Universidad. Darcy Ribeiro. Educación a Distancia. Cederj. 